\title{
Aspirin inhibits osteoclastogenesis by suppressing the activation of NF-KB and MAPKs in RANKL-induced RAW264.7 cells
}

\author{
YAN-PING ZENG, CHAO YANG, YUAN LI, YONG FAN, HONG-JUN YANG, BIN LIU and HONG-XUN SANG
}

Department of Orthopedic Surgery, Institute of Orthopedics, Xijing Hospital, The Fourth Military Medical University, Xi'an, Shaanxi 830054, P.R. China

Received July 9, 2015; Accepted June 3, 2016

DOI: $10.3892 / \mathrm{mmr} .2016 .5456$

\begin{abstract}
Aspirin is a commonly used medicine as an effective antipyretic, analgesic and anti-inflammatory drug. Previous studies have demonstrated its potential effects of anti-postmenopausal osteoporosis, while the molecular mechanisms remain unclear. The effects of aspirin on receptor-activator of nuclear factor $\kappa \mathrm{B}(\mathrm{NF}-\kappa \mathrm{B})$ ligand (RANKL)-induced osteoclasts were investigated in RAW264.7 cells in the current study. Using tartrate-resistant acid phosphatase (TRAP) staining, it was observed that aspirin inhibited the differentiation of RANKL-induced RAW264.7 cells. The mRNA expression of osteoclastic marker genes, including cathepsin K, TRAP, matrix metalloproteinase 9 and calcitonin receptor, were suppressed by aspirin as identified using reverse transcription-quantitative polymerase chain reaction analysis. The immunofluorescence assay indicated that aspirin markedly inhibited NF- $\kappa \mathrm{B}$ p 65 translocation to the nucleus in RANKL-induced RAW264.7 cells. In addition, aspirin also suppressed the phosphorylation of mitogen-activated protein kinases (MAPKs), observed by western blot analysis. Taken together, these data identified that aspirin inhibits osteoclastogenesis by suppressing the activation of NF- $\kappa$ B and MAPKs in RANKL-induced RAW264.7 cells, implying that aspirin may possess therapeutic potential for use in the prevention and treatment of osteoporosis.
\end{abstract}

\section{Introduction}

Osteoclasts are associated with bone homeostasis, and their formation and function is based on the fusion of macrophage precursor cells (1). Receptor-activator of nuclear factor $\kappa B$ $(\mathrm{NF}-\kappa \mathrm{B})(\mathrm{RANK})$ ligand (RANKL) is a tumor-necrosis factor-associated cytokine, and a key osteoclast differentiation factor. Through combination with RANK, RANKL stimulates

Correspondence to: Dr Hong-Xun Sang, Department of Orthopedic Surgery, Institute of Orthopedics, Xijing Hospital, The Fourth Military Medical University, 169 Changle Western Road, Xi'an, Shaanxi 830054, P.R. China

E-mail: sanghongxun_1@163.com

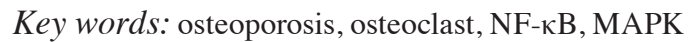

cytoplasmic tumor-necrosis factor receptor-associated factor 6 (2) and correspondingly activates the downstream signaling pathways, including p38 mitogen-activated protein kinase (MAPK), c-jun-N-terminal kinase (JNK), NF- $\mathrm{BB}$ and extra-cellular signal-regulated kinase (ERK) (3-6). As a result of a complex series of signal activation, osteoclast progenitors fused into mature multi-nucleated osteoclasts, expressing a specific group of various gene products, including cathepsin $\mathrm{K}$ (CTSK), tartrate-resistant acid phosphatase (TRAP), calcitonin receptor (CTR) and matrix metalloproteinase 9 (MMP-9) (7).

Osteoporosis is regarded as a metabolic disease, with characteristics of bone mass loss and increased fracture risk, which is a public health problem in an aging society (8). Several anti-resorptive agents including bisphosphonates, calcitonin and estrogen have been used in the treatment of osteoporosis, however, each agent possesses clinical limitations and side-effects include the induction of breast cancer, osteonecrosis and vaginal bleeding $(9,10)$. Thus, a safer therapeutic strategy is required for the use in the prevention and/or treatment of lytic bone diseases including osteoporosis.

Aspirin is a common and safe compound used as an effective antipyretic, analgesic and anti-inflammatory drug. However, additional effects have been identified. Based on an epidemiological survey and preliminary studies, aspirin is suggested to possess anti-postmenopausal osteoporosis effects in the ovariectomized rat model $(11,12)$, which indicate a possible clinical application for aspirin in the prevention of bone loss. However, its detailed molecular mechanisms remain to be fully elucidated.

The current study aimed to investigate the influence of aspirin on osteoclastogenesis in RANKL-induced RAW264.7 cells and identify the molecular mechanisms.

\section{Materials and methods}

Chemicals and reagents. Aspirin (over 99\% purity) and the RANKL and TRAP Staining kits were purchased from Sigma-Aldrich (St. Louis, MO, USA). Fetal bovine serum (FBS; Thermo Fisher Scientific, Inc., Waltham, MA, USA), Dulbecco's modified Eagle's medium (DMEM) and fluorescein isothiocyanate-conjugated secondary antibodies were purchased from Invitrogen (Thermo Fisher Scientific,

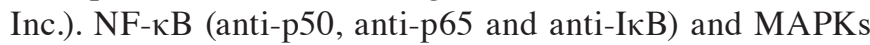
(anti-ERK, anti-JNK and anti-p38) mouse antibodies and 
their phosphorylated antibodies were purchased from Cell Signaling Technology, Inc. (Danvers, MA, USA).

Cell culture. RAW264.7 (TIB-71; American Type Culture Collection, Manassas, VA, USA) murine-macrophage cells were cultured in DMEM with $10 \% \mathrm{FBS}, 100 \mathrm{U} / \mathrm{ml}$ penicillin, and $100 \mu \mathrm{g} / \mathrm{ml}$ streptomycin under $5 \% \mathrm{CO}_{2}$ at $37^{\circ} \mathrm{C}$ in a humidified atmosphere. In each experiment, the cells were grown to $80 \%$ confluence. They were induced by RANKL $(100 \mathrm{ng} / \mathrm{ml})$ in the presence or absence of aspirin for the experiments that followed.

Cytotoxicity assay for aspirin. The cytotoxicity of aspirin was determined by the conventional 3-(4,5-dimethylthiazol-2-yl)-2,5-diphenyltetrazolium bromide (MTT) assay. RAW264.7 cells were seeded into 96-well plates at a density of $10^{4}$ cells/well and cultured as described above for $24 \mathrm{~h}$ in a $37^{\circ} \mathrm{C}, 5 \% \mathrm{CO}_{2}$ incubater. Various concentrations of aspirin were added to each well and the cells were incubated for $2 \mathrm{~h}$, then for $4 \mathrm{~h}$ in $0.5 \mathrm{mg} / \mathrm{ml} \mathrm{MTT}$ solution. The medium in the wells was carefully removed, then $15 \%$ sodium dodecyl sulfate (SDS) was added into each well for solubilization of formazan and measured at $540 \mathrm{~nm}$ with a microplate reader (Bio-Tek Instruments, Inc., Winooski, VT, USA).

TRAP staining. The cells $\left(2 \times 10^{5}\right.$ cells $\left./ \mathrm{ml}\right)$ were plated into a 24-well micro-plate, cultured in DMEM with $10 \% \mathrm{FBS}$, and incubated with different concentration of aspirin $(0.25,0.5$, 1.0 and $1.5 \mathrm{mM})$ in the presence of RANKL $(100 \mathrm{ng} / \mathrm{ml})$ for 5 days. The TRAP Staining kit was used to fix and stain the cells according to the manufacturer's protocol. If TRAP-positive cells had greater than three nuclei, they were regarded as multinucleated osteoclasts. The multinucleated osteoclasts were assessed using a light microscope by counting each field of total three fields. Each group of cells were plated in triplicate, and the mean values were calculated.

Reverse transcription-quantitative polymerase chain reaction $(R T-q P C R)$. The RAW264.7 cells were plated at a density of $2 \times 10^{5}$ cells $/ \mathrm{ml}$ in a 6 -well plate, were incubated with aspirin $(0.25,0.5,1.0$ and $1.5 \mathrm{mM})$ and were cultured for 5 days in DMEM with 10\% FBS in the presence of RANKL (100 ng/ml). Total RNA was separated from the cultured cells using TRIzol (Invitrogen; Thermo Fisher Scientific, Inc.). An RNA PCR kit (Thermo Fisher Scientific, Inc.) was used to reverse transcribe the mRNA into cDNA and five-fold sterile distilled water was added to dilute the resultant cDNA mixture. Diluted cDNA $(0.2 \mu \mathrm{g} / 2 \mu \mathrm{l})$ was subjected to qPCR using SYBR Green I dye according to the manufacturer's instructions. The reaction was conducted in $25 \mu 1 \mathrm{SYBR}^{\circledR}$ premixed-Ex $\mathrm{Taq}^{\mathrm{TM}}$ solution (Takara Bio, Inc., Otsu, Japan), which contained $20 \mu \mathrm{M}$ anti-sense and sense primers (Table I). Primer3 software (version 0.4.0; Whitehead Institute for Biomedical Research, Cambridge, MA, USA) was used to design the primers. Each RT-qPCR experiment was performed in triplicate, and data were collected and normalized to relative expression using Rotor-Gene 6000 Series software, version 1.7.87. All values were normalized to that of glyceraldehyde 3-phosphate dehydrogenase (GAPDH) based on $2^{-\Delta \Delta \mathrm{Cq}}$ formula (13).
Western blot analysis. RAW264.7 cells were plated at a density of $2 \times 10^{5}$ cells $/ \mathrm{ml}$ into 6 -well plates for $18 \mathrm{~h}$, then were pre-treated with aspirin $(0.25,0.5,1.0$ or $1.5 \mathrm{mM})$ for $2 \mathrm{~h}$ prior to treatment with RANKL (100 ng/ml) for $30 \mathrm{~min}$. Ice-cold cell lysis buffer was used to prepare the whole-cell lysates (Cell Signaling Technology, Danvers, MA, USA). The whole cell lysate samples were separated using 10\% SDS-polyacrylimide gel electrophoresis, and then these samples were transferred onto nitrocellulose membranes using the wet-transfer method and blocked in 5\% milk for $1 \mathrm{~h}$ prior to immunoblotting with the following primary antibodies from Cell Signaling Technology, Inc. at 1:2,000 dilution: GAPDH (cat. no. 2118), p65 (cat. no. 8242), phosphorylated (p)-p65 (cat. no.3039), p50 (cat. no.12540), p-p50 (cat. no. 4806),

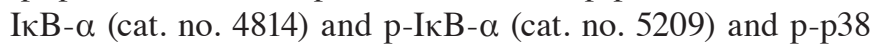
(cat. no. 4511), p38 (cat. no. 8609), p-ERK (cat. no. 4370), ERK (cat. no. 4695), p-JNK (cat. no. 9252) and JNK (cat. no. 9255). The membranes were washed with Tris-buffered saline with Tween-20 (TBST), and then incubated with horseradish peroxidase-conjugated secondary antibody (cat. no. 7074; Cell Signaling Technology, Inc.; 1:2,000 in TBST). GAPDH protein was used as the internal control for the normalization of protein loading. A chemiluminescence detection system (GE Healthcare Life Sciences, Chalfont, UK) was used to detect each protein according to the manufacturer's instructions.

p65 subunit translocations byimmunofluorescence. RAW264.7 cells $\left(2 \times 10^{5}\right.$ cells $\left./ \mathrm{ml}\right)$ were put in 6-well plates on glass cover slips and cultured for $18 \mathrm{~h}$, pre-treated with $1.0 \mathrm{mM}$ aspirin for $2 \mathrm{~h}$ prior to treatment with RANKL $(100 \mathrm{ng} / \mathrm{ml})$ for $30 \mathrm{~min}$. The cells were washed with phosphate-buffered saline (PBS), then fixed in $4 \%$ formaldehyde for $30 \mathrm{~min}$. 1\% Triton X-100 was used for the permeabilization of the cells for $10 \mathrm{~min}$, and then PBS including 5\% bovine serum albumin was also used to block these cells for $30 \mathrm{~min}$. The anti-NF- $\mathrm{B}$ p 65 polyclonal antibodies were added and incubated overnight at $4^{\circ} \mathrm{C}$, followed by $45 \mathrm{~min}$ incubation at room temperature with the fluorescein-conjugated IgG secondary antibody (1:2,000 dilution; cat. no. 4414; Cell Signaling Technology, Inc.). The cover slips were then mounted onto the slides, and fluorescence microscopy (Olympus Corporation, Tokyo, Japan) was used to analyze the fluorescence signal.

Statistical analysis. The results are presented as the mean \pm standard deviation of more than three experiments. One-way analysis of variance with post hoc Dunnett's test was used, and Student's t-test was additionally used to measure the differences among the mean values of normally-distributed data. $\mathrm{P}<0.05$ was considered to indicate a statistically significant difference.

\section{Results}

Effects of aspirin on osteoclast differentiation in the RANKL-stimulated RAW264.7 cells. RAW264.7 cells were cultured with aspirin $(0.25,0.5,1.0$ or $1.5 \mathrm{mM})$ in the presence of $100 \mathrm{ng} / \mathrm{ml}$ RANKL. These cells were stained following 5-day culture (Fig. 1). The results demonstrate that aspirin significantly suppressed the formation of RANKL-induced osteoclast-like cells of RAW264.7 cells in a dose-dependent manner (Fig. 1). In order to exclude the possible cytotoxicity of 
Table I. Primer sequences and product lengths of the genes in reverse transcription-quantitative polymerase chain reaction analysis.

\begin{tabular}{llc}
\hline Gene & \multicolumn{1}{c}{ Primer sequences } & Fragment size $(\mathrm{bp})$ \\
\hline TRAP & F 5'ATCCCTCTGTGCGACATCAACG3' & 214 \\
& R 5'TTAGCGGACAAGCAGGACTCTC3' & 133 \\
CTSK & F 5'TGACTTCCGCAATCCTTAC3' & \\
& R 5'GCAGCAGAAACTTGAACAC3' & 203 \\
MMP-9 & F 5'AGGGAGATGCCCATTTCG3' & 174 \\
CTR & R 5'GCCGTCCTTATCGTAGTCAG3' & 191 \\
& F 5'AGGGCTACTACACAGAGG3' \\
GAPDH & R 5'CGGAGTCAGTGAGATTGG3' & \\
& F 5'ATCACTGCCACCCAGAAG3' & \\
\end{tabular}

TRAP, tartrate-resistant acid phosphatase; CTSK, cathepsin K; MMP-9, matrix metalloproteinase 9; CTR, calcitonin receptor; GAPDH, glyceraldehyde 3-phosphate dehydrogenase; bp, base pair.

A

RANKL (-)



RANKL (+)

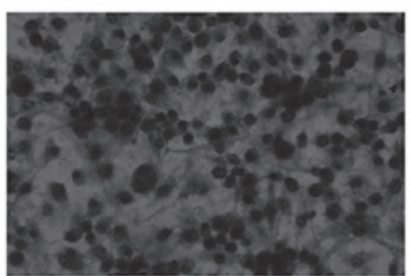

RANKL (+)

RANKL (+)

$+0.25 \mathrm{mM}$

aspirin

+1.0 mM aspirin

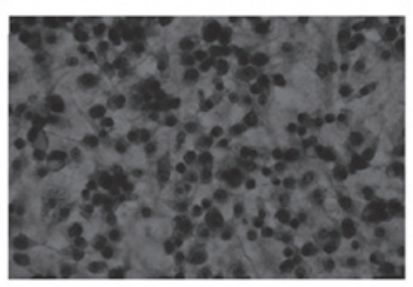

RANKL (+)

+1.5 mM aspirin
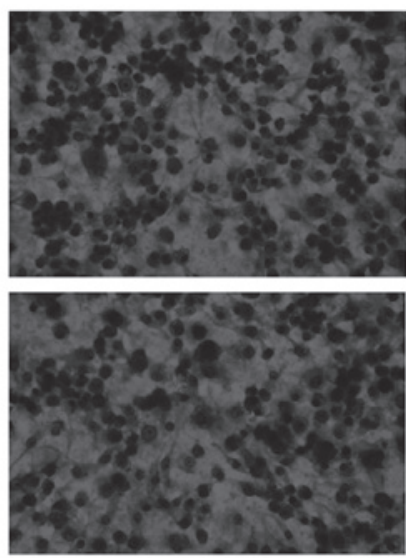

Data 1

B

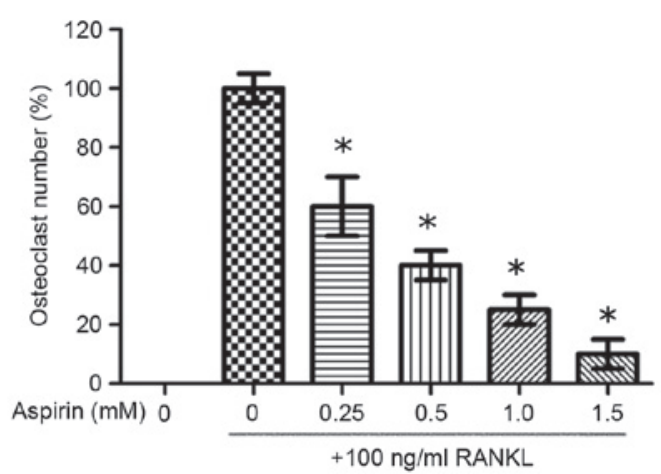

Figure 1. Effect of aspirin on osteoclast differentiation in RANKL-stimulated RAW264.7 cells. RAW264.7 cells (2.0x105 cells/ml) were stimulated with RANKL $(100 \mathrm{ng} / \mathrm{ml})$ for 5 days in the presence of aspirin $(0.25,0.5,1.0$ or $1.5 \mathrm{mM})$. (A) Cells were fixed and stained using the TRAP staining kit. TRAP-positive cells were identified microscopically (original magnification, $x 200$ ). (B) Multinucleated osteoclasts were counted. Values are expressed as the mean \pm standard deviation of triplicate experiments. "P<0.05 vs. RANKL-treated control. RANKL, receptor-activator of nuclear factor $\kappa \mathrm{B}$ ligand; TRAP, tartrate-resistant acid phosphatase. 




Figure 2. Effect of aspirin on RAW264.7 cells viability. A 3-(4,5-dimethylthiazol-2-yl)-2,5-diphenyltetrazolium bromide assay was performed following incubation of RAW264.7 cells with aspirin $(0,0.25,0.5,1.0$ or $1.5 \mathrm{mM})$ for $24 \mathrm{~h}$ at $37^{\circ} \mathrm{C}$ in a $5 \% \mathrm{CO}_{2}$ atmosphere. The results are expressed as a percentage of surviving cells of the control ( $0 \mathrm{mM}$ aspirin). Values are expressed as the mean \pm standard deviation of triplicate experiments.

A



B

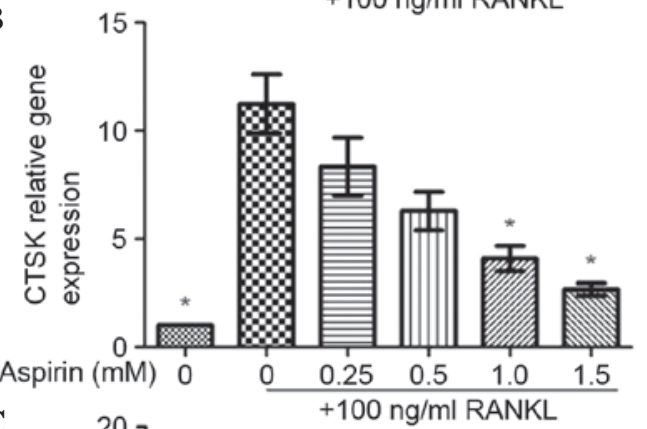

C

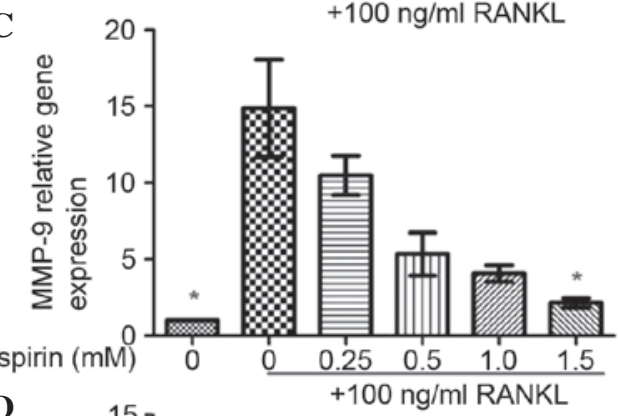

D



Figure 3. Effects of aspirin on RNA expression of osteoclastic marker genes. Total RNA was extracted from RAW264.7 cells cultured for $24 \mathrm{~h}$ in the presence of RANKL $(100 \mathrm{ng} / \mathrm{ml})$ and aspirin $(0.25,0.5,1.0$ or $1.5 \mathrm{mM})$ for $30 \mathrm{~min}$. Relative gene expression of (A) TRAP, (B) CTSK, (C) MMP-9 and (D) CTR was analyzed by reverse transcription-quantitative polymerase chain reaction. Values presented as the mean \pm standard deviation of three independent experiments. ${ }^{*} \mathrm{P}<0.05,{ }^{* *} \mathrm{P}<0.01$ vs. RANKL-treated control. RANKL, receptor-activator of nuclear factor $\kappa \mathrm{B}$ ligand; TRAP, tartrate-resistant acid phosphatase; CTSK, cathepsin K; MMP-9, matrix metalloproteinase 9; CTR, calcitonin receptor.

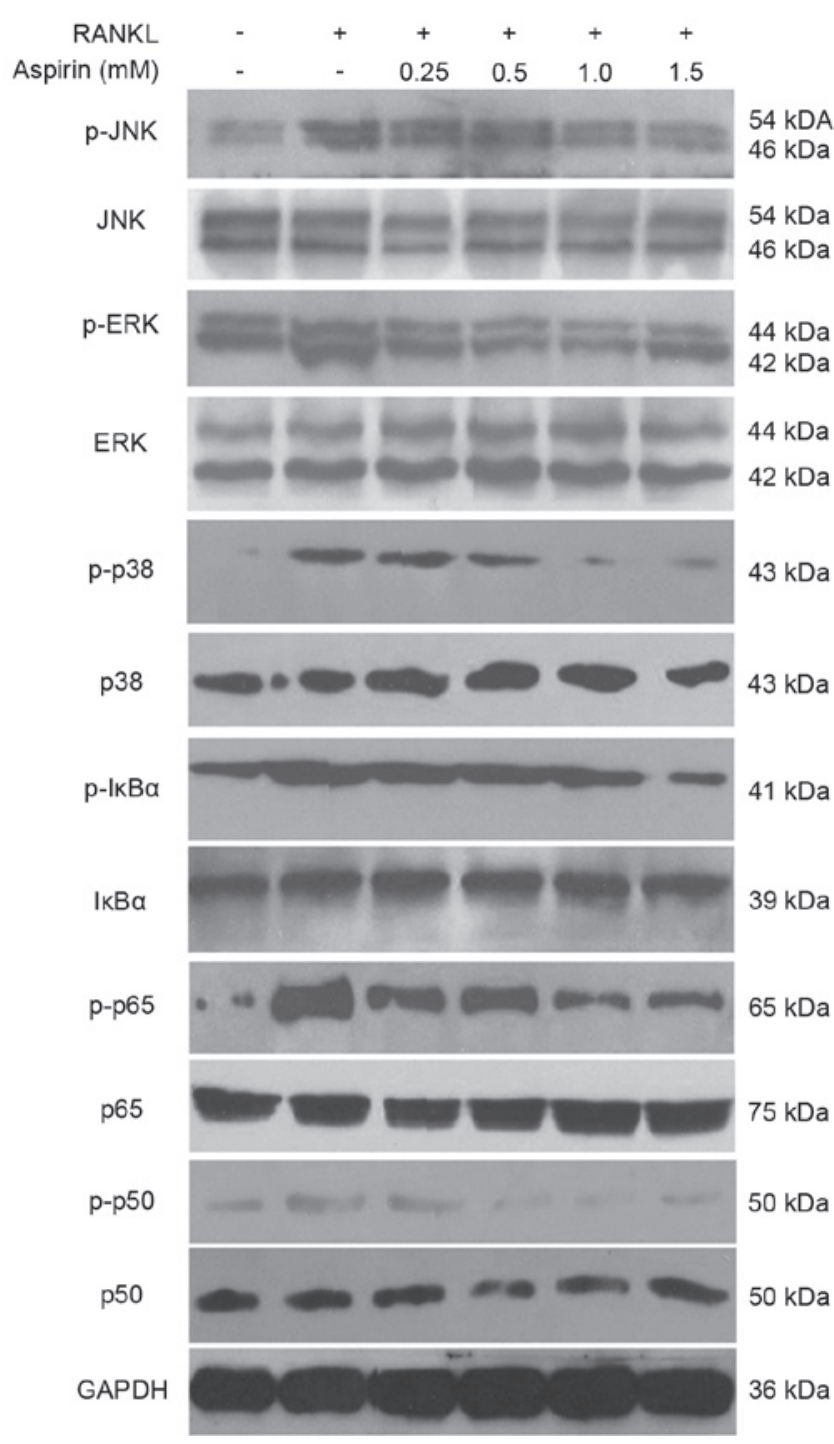

Figure 4. Effects of aspirin on nuclear factor $\mathrm{\kappa B}$ and mitogen-activated protein kinase protein levels in RANKL-stimulated RAW264.7 cells. RAW264.7 cells $\left(2.0 \times 10^{5} \mathrm{cells} / \mathrm{ml}\right)$ were cultured for $18 \mathrm{~h}$, preincubated with aspirin $(0.25$, $0.5,1.0$ or $1.5 \mathrm{mM})$ for $2 \mathrm{~h}$, and then stimulated with RANKL $(100 \mathrm{ng} / \mathrm{ml})$ for $30 \mathrm{~min}$. Protein levels were determined using immunoblotting. RANKL, receptor-activator of nuclear factor $\kappa \mathrm{B}$ ligand; $\mathrm{p}$-, phosphorylated; JNK, c-Jun N-terminal kinases; ERK, extracellular signal-related kinase; IкB $\alpha$, inhibitor of $\kappa \mathrm{B}$; GAPDH, glyceraldehyde 3-phosphate dehydrogenase.

aspirin, its effects on survival of RAW264.7 cells were further assessed. As presented in Fig. 2, aspirin does not exhibit significant cytotoxicity at the concentrations tested. 


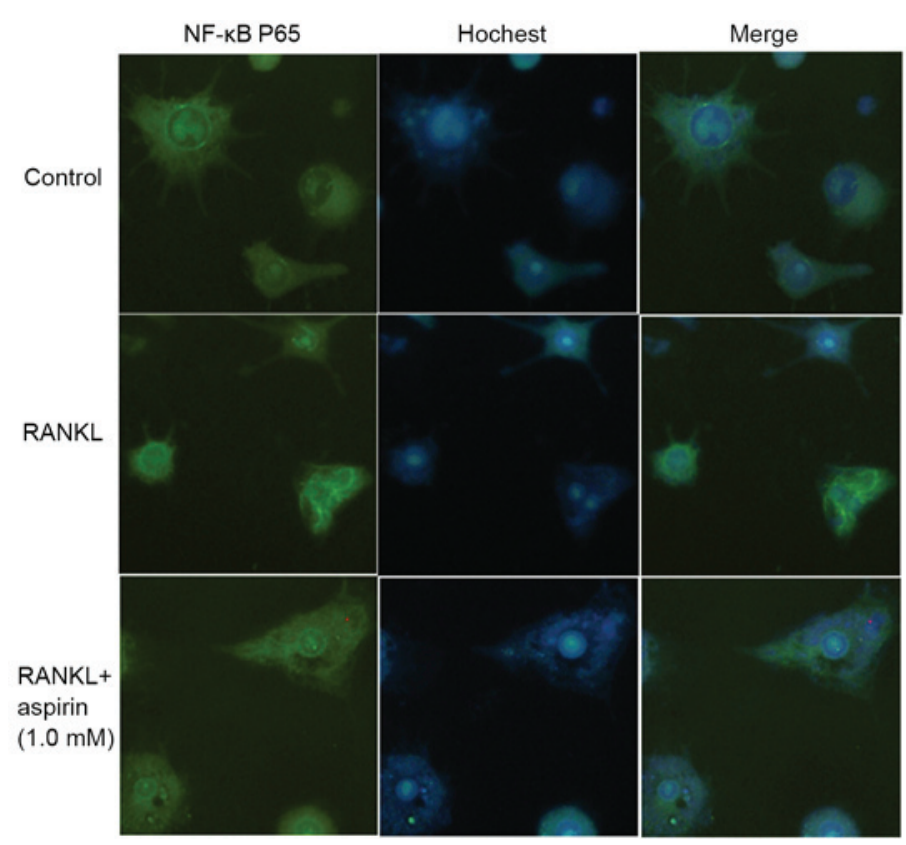

Figure 5. Effect of aspirin on the nuclear translocation of the p65 protein. For the immunofluorescence assay for NF- $\mathrm{B}$ p65 nuclear translocation, cells were pretreated with aspirin for $2 \mathrm{~h}$, then stimulated with $100 \mathrm{ng} / \mathrm{ml}$ RANKL for $30 \mathrm{~min}$. Images, from left to right, represent the p65 protein, nucleus and merged images with p65 protein and the nucleus. p65 was detected by DyLight 488-labeled immunostaining (green); nuclei were stained by Hoechst (blue). NF- $\kappa$ B, nuclear factor $\kappa \mathrm{B}$; RANKL, receptor-activator of $N F-\kappa B$ ligand.

The RNA expression of osteoclastic markers in RANKL-stimulated RAW264.7 cells. In order to analyze the function of aspirin in the differentiation of osteoclasts, its effects on the RNA expression levels of the osteoclastic marker gene were assessed by RT-qPCR analysis. Osteoclastic markers, including MMP-9, TRAP, CTR and CTSK, were significantly upregulated following RANKL treatment. This RANKL-mediated upregulation of osteoclastic marker gene expression was reduced by the addition of aspirin (Fig. 3).

Effects of aspirin on $N F-\kappa B$ activation in RANKL-stimulated $R A W 264.7$ cells. To ascertain whether aspirin suppresses the phosphorylation and degradation of I $\kappa$ B in RANKL-induced RAW264.7 cells, RAW264.7 cells were pre-treated for $2 \mathrm{~h}$ in the presence of aspirin, and the I $\mathrm{B}-\alpha$ protein level was confirmed following 30 min additional exposure with RANKL $(100 \mathrm{ng} / \mathrm{ml})$. It was identified that aspirin markedly suppressed the RANKL-induced degradation in addition to the phosphorylation of I $\kappa \mathrm{B}-\alpha$ (Fig. 4). In addition, the phophorylation of p50/p65 was examined and aspirin was identified to markedly reduce RANKL-induced p50/p65 phosphorylation (Fig. 4).

Effects of aspirin on the phosphorylation of MAPKs in RANKL-stimulated RAW264.7 cells. In order to confirm whether the MAPK signaling pathway serves an important role in the inhibition of osteoclastogenesis by aspirin, the phosphorylation of three MAPK signaling molecules, including ERK, p38 and JNK, were evaluated. It is was observed that following RANKL activation, the proteins were phosphorylated (Fig. 4). Aspirin markedly suppressed p-ERK, p-p38 and p-JNK stimulation in a dose-dependent manner (Fig. 4). However, the quantity of unphosphorylated JNK, ERK and p38 did not appear to be affected by aspirin treatment with RANKL.
Effects of aspirin on p65 translocation to the nucleus in RANKL-stimulated RAW 264.7 cells. The effects of aspirin on RANKL-induced NF- $\mathrm{B}$ p 65 nuclear translocation were assessed, due to the fact that p65 translocation to the nucleus is essential for $\mathrm{NF}-\kappa \mathrm{B}$-dependent transcription following RANKL stimulation. Thus, an indirect immunofluorescence assay was used to analyze the NF- $\kappa$ B p65 translocation. As presented in Fig. 5, compared with untreated cells, marked intracellular-p65 translocation to the nucleus from the cytoplasm was induced by RANKL in RAW264.7 cells. The aspirin pre-treated cell were observed to exhibit inhibition of this type of translocation.

\section{Discussion}

Osteoclasts are present only in the bone, and serve an effective function in bone-resorption. The intervention of functions and differentiation of osteoclasts are regarded as the treatment for bone-metabolic diseases like osteoporosis (14). RANKL signaling triggers osteoclast differentiation and has been significant for treating pathological bone-loss. The combination of RANKL and its receptor, RANK, rapidly stimulates MAPKs, including p38, ERK and JNK, which are all essential for the differentiation, survival and activation of the osteoclasts (15-17). These activated MAPKs lead to the stimulation of transcription factors such as nuclear factor of activated T-cells, cytoplasmic 1 . In the current study, the rapid phosphorylation of p38, ERK and JNK following treatment with RANKL in RAW264.7 cell were suppressed by aspirin through a dose-dependent manner, indicating that aspirin may suppress the MAPK signaling cascade.

It is has been previously demonstrated that hematopoietic cells of monocyte-macrophage lineage fuse to form osteoclasts in the early stage of differentiation (18). The final 
differentiation manifestations include alterations in gene expression of characteristic markers including TRAP, CTSK, MMP-9 and CTR, morphological conversions into multinucleated cell and the ability of development of bone resorption lacunae (19-22). Aspirin reduced the RANKL-induced TRAP, CTSK, MMP-9 and CTR gene products in a dose-dependent manner, indicating an osteoclast differentiation inhibiting effect.

$\mathrm{NF}-\kappa \mathrm{B}$ has been reported to be a crucial transcription factor in RANKL-induced osteoclastogenesis (23). NF- $\kappa \mathrm{B}$ is not active in the cytosol due to its connections with $I \kappa B$, however it becomes active once the phosphorylation and corresponding degradation of I $\kappa \mathrm{B}$ occurs (24). In unstimulated cells, $\mathrm{NF}-\kappa \mathrm{B}$ is composed of the $\mathrm{p} 65 / \mathrm{p} 50$ heterodimer and is combined with the inhibitor protein $\mathrm{I} \kappa \mathrm{B}$. RANKL activation results in the activation of the kinase of $\mathrm{I} \kappa \mathrm{B}$ and $\mathrm{I} \kappa \mathrm{B}-\alpha$ phosphorylation. The latter is effected by the proteasomes, and the dissociative p65 subunit enters the nucleus and binds with at a specific position on the DNA, then target gene transcription is initiated (25). The current study observed that aspirin was able to suppress the degradation of I $\mathrm{B}-\alpha / \mathrm{p} 65$ translocation to the nucleus in the RANKL-induced RAW264.7 cells, which were detected by western blotting and immunofluorescence, implying that the $\mathrm{NF}-\kappa \mathrm{B}$ pathway may serve a role in the inhibition of osteoclastogenesis of the RANKL-induced RAW264.7 cells.

In conclusion, the current study demonstrated that aspirin suppressed the osteoclastogenesis of RANKL-induced RAW264.7 cells. Aspirin additionally reduced RANKL-induced expression of the osteoclastic marker genes. Additionally, aspirin was observed to suppress RANKL-induced activation of $\mathrm{p} 38, \mathrm{JNK}$ and NF- $\kappa \mathrm{B}$. Further study is required to clarify the efficacy of aspirin in the treatment of disease in vivo, however the results of the current study indicate that it may have potential for the development of a therapeutic drug for osteoporosis.

\section{References}

1. Boyle WJ, Simonet WS and Lacey DL: Osteoclast differentiation and activation. Nature 423: 337-342, 2003.

2. Armstrong AP, Tometsko ME, Glaccum M, Sutherland CL, Cosman D and Dougall WC: A RANK/TRAF6-dependent signal transduction pathway is essential for osteoclast cy toskeletal organization and resorptive function. J Biol Chem 277: 44347-44356, 2002.

3. Wei S, Teitelbaum SL, Wang MW and Ross FP: Receptor activator of nuclear factor-kappa $b$ ligand activates nuclear factor-kappa b in osteoclast precursors. Endocrinology 142: 1290-1295, 2001.

4. Matsumoto M, Sudo T, Saito T, Osada H and Tsujimoto M: Involvement of p38 mitogen-activated protein kinase signaling pathway in osteoclastogenesis mediated by receptor activator of NF-kappa B ligand (RANKL). J Biol Chem 275: 31155-31161, 2000.

5. David JP, Sabapathy K, Hoffmann O, Idarraga MH and Wagner EF: JNK1 modulates osteoclastogenesis through both c-Jun phosphorylation-dependent and -independent mechanisms. J Cell Sci 115: 4317-4325, 2002.

6. Lee SE, Woo KM, Kim SY, Kim HM, Kwack K, Lee ZH and Kim HH: The phosphatidylinositol 3-kinase, p38, and extracellular signal-regulated kinase pathways are involved inosteoclast differentiation. Bone 30: 71-77, 2002.
7. Koga T, Inui M, Inoue K, Kim S, Suematsu A, Kobayashi E, Iwata T, Ohnishi H, Matozaki T, Kodama T, et al: Costimulatory signals mediated by the ITAM motif cooperate with RANKL for bone homeostasis. Nature 428: 758-763, 2004.

8. Baltas CS, Balanika AP, Raptou PD, Tournis S and Lyritis GP; Hellenic guidelines on bone densitometry working group: Clinical practice guidelines proposed by the Hellenic Foundation of Osteoporosis for the management of osteoporosis based on DXA results. J Musculoskelet Neuronal Interact 5: 388-392, 2005.

9. Valverde P: Pharmacotherapies to manage bone loss-associated diseases: A quest for the perfect benefit-to-risk ratio. Curr Med Chem 15: 284-304, 2008

10. Li L and Seeram NP: Further investigation into maple syrup yields 3 new lignans, a new phenylpropanoid, and 26 other phytochemicals. J Agric Food Chem 59: 7708-7716, 2011.

11. Bauer DC, Orwoll ES, Fox KM, Vogt TM, Lane NE, Hochberg MC, Stone K and Nevitt MC: Aspirin and NSAID use in older women: Effect on bone mineral density and fracture risk. Study of Osteoporotic Fractures Research Group. J Bone Miner Res 11: 29-35, 1996.

12. Chen ZW, Wu ZX, Sang HX, Qin GL, Wang LS, Feng J, Wang J, Li XJ, Wang JC and Zhang D: Effect of aspirin administration for the treatment of osteoporosis in ovariectomized rat model. Zhonghua Yi Xue Za Zhi 91: 925-929, 2011 (In Chinese).

13. Livak KJ and Schmittgen TD: Analysis of relative gene expression data using real-time quantitative PCR and the 2(-Delta Delta C(T)) method. Methods 25: 402-408, 2001.

14. Raisz LG: Pathogenesis of osteoporosis: Concepts, conflicts, and prospects. J Clin Invest 115: 3318-3325, 2005.

15. Grigoriadis AE, Wang ZQ, Cecchini MG, Hofstetter W, Felix R, Fleisch HA and Wagner EF: c-Fos: A key regulator of osteoclast-macrophage lineage determination and bone remodeling. Science 266: 443-448, 1994.

16. Mansky KC, Sankar U, Han J and Ostrowski MC: Microphthalmia transcription factor is a target of the $\mathrm{p} 38$ MAPK pathway in response to receptor activator of NF-kappa B ligand signaling. J Biol Chem 277: 11077-11083, 2002.

17. Gingery A, Bradley E, Shaw A and Oursler MJ: Phosphatidylinositol 3-kinase coordinately activates the MEK/ERK and AKT/NFkappaB pathways to maintain osteoclast survival. J Cell Biochem 89: 165-179, 2003.

18. Mohamed SG, Sugiyama E, Shinoda K, Taki H, Hounoki H, Abdel-Aziz HO, Maruyama M, Kobayashi M, Ogawa H and Miyahara T: Interleukin-10 inhibits RANKL-mediated expression of NFATc1 in part via suppression of c-Fos and c-Jun in RAW264.7 cells and mouse bone marrow cells. Bone 41: 592-602, 2007.

19. Anusaksathien O, Laplace C, Li X, Ren Y, Peng L, Goldring SR and Galson DL: Tissue-specific and ubiquitous promoters direct the expression of alternatively spliced transcripts from the calcitonin receptor gene. J Biol Chem 276: 22663-22674, 2001.

20. Motyckova G, Weilbaecher KN, Horstmann M, Rieman DJ, Fisher DZ and Fisher DE: Linking osteopetrosis and pycnodysostosis: Regulation of cathepsin $\mathrm{K}$ expression by the microphthalmia transcription factor family. Proc Natl Acad Sci USA 98: 5798-5803, 2001.

21. Reddy SV, Hundley JE, Windle JJ, Alcantara O, Linn R, Leach RJ, Boldt DH and Roodman GD: Characterization of the mouse tartrate-resistant acid phosphatase (TRAP) gene promoter. J Bone Miner Res 10: 601-606, 1995.

22. Choi HJ, Park YR, Nepal M, Choi BY, Cho NP, Choi SH, Heo SR, Kim HS, Yang MS and Soh Y: Inhibition of osteoclastogenic differentiation by Ikarisoside A in RAW 264.7 cells via JNK and NF-kappaB signaling pathways. Eur J Pharmacol 636: 28-35, 2010.

23. Bharti AC, Takada Y and Aggarwal BB: Curcumin (diferuloylmethane) inhibits receptor activator of NF-kappa B ligand-induced NF-kappa B activation in osteoclast precursors and suppresses osteoclastogenesis. J Immunol 172: 5940-5947, 2004.

24. Ghosh S and Karin M: Missing pieces in the NF-kappaB puzzle. Cell 109 (Suppl): S81-S96, 2002.

25. Karin M, Yamamoto Y and Wang QM: The IKK NF-kappa B system: A treasure trove for drug development. Nat Rev Drug Discov 3: 17-26, 2004. 